\title{
Research on the Application of Information Technology in School Sports
}

\author{
Du Yunyun \\ Department of Sports Engineering\&Information, Wuhan Institute of Physical Education, Wuhan, China \\ dyunyun@wipe.edu.cn
}

\begin{abstract}
The paper analyses the role of information technology in the P.E, training and management and analyzes the theoretical and practical basis for the application of information technology in the school sports.It also proposes measures to fully exert the function of information technology in the school sports.
\end{abstract}

Keywords-Information technology;school sports; P.E; Sports training; Sports management

\section{INTRODUCTION}

As the main component of our country's sports system, school sports is an important means and channel to realize the purposes and tasks of our country's sports, is a strategic point and base to develop national fitness sport, and plays an important role in cultivating comprehensively-developed new century sports talents. The application of information technology in school sports becomes wider and wider, and the role is more obvious, so further promoting the application of information technology in school sports is the need of social development.

\section{THE APPLICATION OF INFORMATION TECHNOLOGY IN} SCHOOL SPORTS IS FAVORABLE TO IMPROVE THE SPORTS TEACHING QUALITY, AND CULTIVATE THE INNOVATIVE SPIRIT AND PRACTICAL ABILITY OF STUDENTS

A. Helpful to optimize the environment of sports education and the breakthrough of key points and difficulties of sports education

As a modern teaching manner, multimedia computer aided sports education has a very important meaning and role for optimizing sports class teaching, exciting students' sports learning motivity and interest, deepening students' understanding to action concept and sports theoretical knowledge, and improving sports education quality. Teachers can visually and realistically reflect the dynamic change process of technical actions, attract students' hearing and vision, and inducing students' thinking to achieve the objective of exciting students' learning motivity via multimedia such as picture, animation, image, and voice. Teachers spent much time to explain and demonstrate the abstract and difficult contents peviously, but currently can let the students understand them easily in visual and concrete manner with multimedia technology. Multimedia instruction with multimedia technology, teachers excite students' thirst for knowledge, in which the students' attention are attracted by frame and animation and they enter into the most pleasant stage of learning in a cheerful mood.

Therefore, applying information technology to sports education and making it become the extension and sublimation of traditional teaching can make the students willing and actively to learn. At the same time, information technology promotes the optimization of sports education links, such as explanation, demonstration, working, examination, and feedback, and achieves the objectives of optimizing the sports education environment and enhancing the teaching quality by its convenient interactivity and sharing property.

B. The application of information technology in school sports is favorable for the intercourse between teachers and students, and favorable to consolidate the effect of sports teaching

The interactivity of network in information technology promotes the intercourse between sports teachers and students or students, and supports the creation of learning and exercising environment and the formation of learning and exercising team. By sufficiently utilizing the conditions of massive resources, diversified forms, interactive intercourse, and active learning provided by the modern information technology, lay stress on the excitation of learning initiative of students, on the cooperation and interaction of learning and exercise, cultivate the abilities of students to obtain materials from network resources and innovate continuously, and improve the information and sports accomplishment of students during teaching.

\section{Helpful to enhance their abilities to analyze and solve problems}

The traditional sports education mainly adopts the teaching mode of "teacher explains and student practices". The educational psychology research indicated that, the most practical and active factor is the interest of cognition in learning motivation, the things learned under interest are often grasped quickly and firmly; the traditional sports education mode is "the absolute authority of the teachers", which is carried out mainly by the teachers' active transfer and students' passive absorption, ignores the principles of teaching students in accordance of their abilities, personalities and behaviors, and the students can only absorb knowledge and training methods under the fixed thinking mode of gym teachers, which greatly restricts the initiative and thinking space of learning and training of students.

But with the help of information technology aided sports education to make the various sports theoretical knowledge, sports techniques, technical difficulties and key points, common erroneous actions into courseware for the students to see and learn, and discuss, present, analyze, and solve problems, during which to cultivate the students' autonomy and initiative of learning and training, and enhance their abilities to analyze and solve problems. Applying information technology to sports education to make the contents and teaching methods of sports education improve continuously, i.e. using the student-oriented 
teaching method, which will be helpful to enhance the compositive qualities of students of gym schools.

\section{INFORMATION TECHNOLOGY PROMOTES THE SCIENTIFIC} TRAINING OF ATHLETIC SPORTS

\section{A. Helpful to promote the scientific selection}

Selecting the athletes suitable for corresponding sports in scientific ways is the precondition to obtain an excellent achievement in sports field. Scientific selection is the primary task of modern sport training. Establishing the ideal mathematical model of excellent athletes quantitatively and formulating various standards for selecting adolescent athletes by using information technology and combined with generics, biochemistry, biomechanics, mathematics, and biotechnology are helpful for scientific selection.

\section{B. Helpful to improve the teaching efficiency of action learning}

In sports, many techniques are complicated in structure and need to be finished within a moment, and some are abnormal such as aerial actions in track and field jumping events, continuous actions of supporting and jumping in gymnastics, swing backward of horizontal bar; the final force applying sequence of shot in throwing events; physical extension of hang style long jump and coxa-turning of bend over high jump in jumping events, all of which are never existent in our daily life and make teaching very difficult. On one hand, the teachers' demonstration is restricted with large randomness due to various aspects such as their comprehension on action essentials, age, site physical status, mental factor or their other own conditions, etc; on the other hand, the students' observation angle and opportunity are also restricted greatly, and they are very difficult to clearly observe how the teachers make demonstration as per the action requirements due to the quickness and difficulty of actions, which inevitably will influence the students' learning.

Via the multimedia courseware made by computer, to express the technical links, which teachers are difficult to demonstrate clearly, by animation or image in slow motion, pause, and replay, etc. combined with explanation and demonstration by the help of the modern education technology, in this way can help the students see clearly the technical details of actions at each moment, and the teachers can explain the essentials of each action, demonstrate the full process of the whole action, hence catch the key parts of actions, give prominence to the key and difficult points, as well as establish action representation faster and more comprehensively, improved the teaching efficiency of action learning in cognition stage and shortened the teaching process.

\section{Information technology makes the sport technology diagnosis more accurate}

Information technology makes the sport technology diagnosis more accurate, which is favorable to improve the sport training achievement. For example, in water sports, extract the position and motion information of racing boats during running, and realtime acquire the GPS data of racing boats by utilizing GPS, obtain the track, speed and acceleration curve, speed and height curve after treatment, and via analysis obtain the motion states and technical indicators of racing boats in each navigation stage for reference by the athletes and coach. In track and field, by using computer technology diagnosis system, shoot the motion track and state of object in several seconds after thrown out with high-speed video recorder, display at any times various motion parameters such as acceleration, speed angle, and angular speed, compare the practical parameters with the optimized data in memory, timely improve the throwing poses and motions of athletes, and improve the sport training achievement.

\section{Helpful to monitor the physical ability of athletes}

An important link during sport training is to monitor the physical ability of athletes, for example, to monitor the physiological and biochemical indexes such as heart rate and heart electricity, and via computer treatment feed back and adjust the sport training load to achieve scientific training effect.

\section{THE APPLICATION OF INFORMATION TECHNOLOGY IS AN EFFECTIVE MEANS TO REALIZE SCIENTIFIC MANAGEMENT OF SCHOOL SPORTS}

\section{A. Helpful to promotes the scientific management of P.E}

Carry out scientific management to the formulation and implementation of various sports teaching plans by computer and network technology to make high-speed and efficient management. Reduce emotional influence by network platform and computer statistical software to make the checking and evaluation of sports teaching more objective and true. The analysis and treatment of feedback information are more timely, accurate, and effective, improved the management level.

\section{B. Information technology make the management of sports expenses, sites, and equipment more normative and efficient}

Develop relevant management application software by information technology to make the management of sports expenses, sites, and equipment more normative and efficient. Open and publish the expenses necessary for the procurement of sports equipment, maintenance and expansion of sport sites, and various sports activities to the faculty in time and detail by campus network, accepted the supervision of faculty and made the school's financial management system more transparent and strict. Manage the sports equipment and goods in fixed assets, material, and low value and easily worn-out article by computer, and improve the management system such as procurement, storage, borrow, and maintenance, made the management getting twice the result with half the effort.

\section{Making the management of sports working files and intelligence data more comprehensive and orderly}

In the management of school sports, must sufficiently regard and seriously conduct the accumulation, collation, statistics, and analysis of files and data, and exert its information storage and feedback roles. Store the files of superior educational departments, sports departments, and the school by category and make them into electronic files with computer-aided management software, let the file management more orderly and the reference more convenient. Classify the data timely and automatically, judge rapidly and accurately, and provide general mathematical statistical analysis indexes, 
achievement ordering and summarization, and statistical form printing, etc. by database management system software.

Sports intelligence resources are the information base of school sports. Along with the fast development of international internet, timely collect, collate, store, and utilize the massive sports information by network is helpful to improve the works and scientific research level of school sports.

\section{SUGGESTION}

A. Gym teachers should actively change their teaching conceptions and improve their ability of applying information technology

This is an information age, along with the extensive application of information technologies, the traditional teaching modes, methods, and means sure will change essentially. Gym teachers should actively meet challenges, change conceptions, improve computer application skills, learn and grasp the modern teaching methods and means to become a high-quality gym teacher adapting to the education at information age.

\section{B. Sports schools should increase the force on information technology aided sports education}

There is still a large development space in the informatization of school sports in our country. Schools should rationally establish the plan to popularize information technology to school sports, enlarge the development and application of sports teaching software, sport training assistant software, and sports management software, lay stress on the integration and utilization of information resources, and sufficiently exert the advantages of network technology, expedited the construction and development of school sports.

\section{PROSPECT}

Our country has gained some achievements in the application of information technology in school sports. School sports is at an important position in our country's strategy of constructing a powerful sports country, we should further strengthen the application of information technology in school sports, promote modern sports teaching, scientific sports training, and normative sports management, and sufficiently exert the role of school sports in our country’s sports system.

\section{REFERENCES}

[1] $\mathrm{Xu}$ Guozhong.Study on Integration Strategies of Information Technology and Sports Teaching of Colleges and Universities [J].China Afterschool Education, 2010,(18).

[2] Yu Qianchun.Study on Management Informatization of Sports Teaching of Colleges and Universities[J].Journal of Anhui Sports Science,2007,(01).

[3] Chang Chao.Analysis on Application of Modern Information Technology in Sports Teaching of Colleges and Universities[J].Journal of Chifeng College (Natural Science Edition) ,2010,(05). 